\title{
Nitric Oxide-Releasing Aspirin Decreases Vascular Injury by Reducing Inflammation and Promoting Apoptosis
}

\author{
Jun Yu, Radu Daniel Rudic, and William C. Sessa \\ Department of Pharmacology and Program in Vascular Cell Signaling and Therapeutics (JY, WCS), Boyer Center for \\ Molecular Medicine, Yale University School of Medicine, New Haven, Connecticut; and the Center for Experimental \\ Therapeutics (RDR), University of Pennsylvania School of Medicine, Philadelphia, Pennsylvania
}

\begin{abstract}
SUMMARY: Endothelial dysfunction, defined as a deficit in the bioavailability of nitric oxide (NO), occurs as sequelae of many vascular diseases; however, the utility of supplementing NO to obviate the extent of disease is understudied. Here, we examined if prolonged treatment with an NO-releasing form of aspirin (NO-ASA) can influence neointimal remodeling of femoral arteries of hypercholesterolemic ApoE (-/-) mice. Treatment of ApoE (-/-) mice with NO-ASA, but not aspirin (ASA), improved neointimal remodeling post-injury. NO-ASA treatment increased lumen diameters and reduced intimal-to-medial ratios of injured femoral arteries compared with ASA- or vehicle-treated mice. The reduction in lumen diameter in NO-ASA-treated mice was associated with a marked reduction in CD45-positive inflammatory cells and an increased number of TUNEL-positive cells. Thus, NO-ASA, by virtue of releasing $\mathrm{NO}$, can reduce vascular inflammation and promote apoptosis during vascular remodeling associated with neointimal thickening. (Lab Invest 2002, 82:825-832).
\end{abstract}

E ndothelium-derived nitric oxide (NO) is an important regulator of vessel homeostasis. In addition to its well defined role as a smooth muscle relaxant, $\mathrm{NO}$ has been implicated in the regulation of other processes in the vessel wall, including coagulation, inflammation, vessel remodeling, and angiogenesis (Moncada, 1997; Papapetropoulos et al, 1999). Clinically, endothelial dysfunction, manifested by impaired endothelium-dependent vasomotor responses, occurs before the onset and throughout the progression of many cardiovascular diseases, including atherosclerosis and restenosis (Rudic and Sessa, 1999). Evidence supporting an intimate relationship between endothelial dysfunction and disease progression is suggested by studies showing that treatment of patients with angiotensin-converting enzyme inhibitors (Giugliano et al, 1998; Mancini et al, 1996) or statinbased drugs (Vaughan et al, 1996) improves endothelial dysfunction concomitantly with delaying disease progression.

Although, the loss of NO bioreactivity is commonly observed in cardiovascular diseases (Harrison, 1997), there is little experimental evidence indicating that augmentation of $\mathrm{NO}$ through the administration of $\mathrm{NO}$

DOI: 10.1097/01.LAB.0000018828.61722.BD

Received January 7, 2002.

This work was supported by grants from the National Institutes of Health (RO1 HL57665, HL61371, and HL64793 to WCS).

Address reprint requests to: Dr. William C. Sessa, Department of Pharmacology and Program in Vascular Cell Signaling and Therapeutics, Boyer Center for Molecular Medicine, Yale University School of Medicine, 295 Congress Avenue, New Haven, CT 06536.E-mail:william.sessa@yale.edu donor drugs influences the progression of vascular disease. Indirect approaches attempting to elevate NO levels through L-arginine supplementation (Cooke et al, 1991; Girerd et al, 1990; Vermeersch et al, 2001) or using NOS gene transfer have shown beneficial effects in certain models of hypercholesterolemia and restenosis (Tzeng et al, 1996; von der Leyen et al, 1995). However, it is not clear if L-arginine supplementation truly improves dysfunction through the NO synthase pathway and the feasibility therapeutic gene transfer is still questionable.

A newer approach to deliver $\mathrm{NO}$ in a sustained and predictable manner is by the usage of $\mathrm{NO}$ adducts coupled to known pharmacophores such as aspirin (ASA) or nonsteroidal anti-inflammatory drugs (NSAIDs) (Wallace et al, 1994, 1995a). Initially designed as drugs to release $\mathrm{NO}$ thereby providing cytoprotection to the gastric mucosa to obviate the irritant actions of ASA and NSAIDs, this class of compounds may also exert a beneficial effect on the cardiovascular system (Muscara et al, 2000; Napoli et al, 2001; Wallace et al, 1995b, 1999). Thus, the goal of the present study was to examine if the NO-releasing form of aspirin (NO-ASA) could influence injuryinduced neointima formation and vessel remodeling in a model of atherosclerosis in mice.

\section{Results}

Because atherosclerotic mice exhibit a greater neointimal proliferative response to injury than do normal mice and more accurately reflect the situation closer to human restenosis, we chose $\mathrm{ApoE}(-/-)$ mice as a 
model. As seen in Table 1, all mice were clearly hypercholesterolemic and there were no significant differences among groups before surgery $(p>0.05)$ and no significant difference due to the treatment regimen $(p>0.05)$.

Figure 1 depicts representative cross-sections showing the histologic appearances (hematoxylin/eosin (H\&E), left panels; elastic/Van Gieson's (EVG) stain, right panels) of injured vessels from vehicle- $(\mathrm{V}$; in $\mathrm{A}$ and $B$ ) aspirin- (ASA; in Fig. 1, C and D), and nitroaspirin- (NO-ASA; in Fig. 1, E and F) treated mice. Injury of the femoral artery provoked an increase in neointimal cellularity in V-, ASA-, and NO-ASA-treated mice as seen in Figure 1, A to $F$, in V-treated mice, neointimal expansion resulted in near luminal occlusion of the vessel (A); an effect more clearly delineated by intense staining of the internal elastic fibers (B). Chronic treatment of mice with NO-ASA, but not ASA alone, reduced neointima formation and increased lumen area (Fig. 1, C to F). Quantitative assessment of the neointimal remodeling showed that external elastic lamina diameters and medial areas did not vary in the three treatment groups; however, the intimal area was markedly reduced by $50 \%$ in the NO-ASA-treated group compared with $\mathrm{V}$ (Table 2). ASA appeared to exert a slight, nonsignificant effect in reducing intimal areas. The beneficial effect of NO-ASA in reducing neointima was associated with a greater lumen area (Fig. 2A) and decreased intima/media (I/M) ratios (Fig. 2B). I/M ratios in ASA-treated mice were different from $\mathrm{V}$-treated mice due to the slight decrease in intimal area (Table 2). However, no individual parameter was significantly different from $\mathrm{V}$-treated mice.

To elucidate potential mechanisms that may contribute to the beneficial actions of NO-ASA, the presence of CD45-positive leukocytes in injured vessels from V-, ASA-, and NO-ASA-treated mice were examined. As seen in Figure $3 A$ and inset, many CD45positive immunoreactive cells were found throughout the media and adventitia of V-treated mice. Treatment with ASA reduced the number of CD45-positive cells, especially in the media of injured vessels (Fig. 3B and inset), whereas NO-ASA treatment almost completely eliminated CD45-positive cells from both media and adventitia (Fig. 3C and inset). These data are quantified in Figure 3D.

To examine if NO-driven apoptosis could account for the decrease in intimal thickening, we quantified apoptotic cells in the injured vessels using TUNEL

Table 1. Plasma Total Cholesterol Levels in Blood from Three Treatment Groups

\begin{tabular}{llcr}
\hline & & \multicolumn{2}{c}{ Total cholesterol $(\mathrm{mg} / \mathrm{dl})$} \\
\cline { 3 - 4 } Group & $n$ & Injury day & \multicolumn{1}{c}{ Day killed } \\
\hline Vehicle & 4 & $281.35 \pm 37.54$ & $464.975 \pm 35.30$ \\
ASA & 4 & $371.50 \pm 38.49$ & $488.075 \pm 25.37$ \\
NO-ASA & 4 & $339.83 \pm 25.37$ & $479.65 \pm 13.89$ \\
\hline
\end{tabular}

Data are expressed as mean $\pm \mathrm{SEM}$.

$n$, number of mice. staining. As seen in Figure 4A, NO-ASA markedly enhanced the number of TUNEL-positive cells in the vessel wall compared with $\mathrm{V}$ - and ASA-treated mice. The proapoptotic effect of NO-ASA can be readily seen as observed by darkly stained nuclei in the media of the remodeled femoral in Figure 4B. Thus, NO-ASA can reduce neointimal progression via a reduction in local inflammation and stimulation of apoptosis and turnover of cells in the injured vessel.

\section{Discussion}

The central findings of our study show that NO-ASA, but not ASA, can reduce injury-evoked neointimal expansion in injured femoral arteries of ApoE(-/-) mice. The reduction in neointima is associated with a marked deficit in inflammatory cells recruited to the injured vessel and an increase in TUNEL-positive cells. Our study, in conjunction with a recently published report in a different model of vascular injury (Napoli et al, 2001), supports the idea that NO-ASA may be a useful adjunct to treat restenosis by reducing vascular inflammation and cell proliferation and by promoting apoptosis.

Considering the fundamental role of NO in cardiovascular control mechanisms and its effect on platelets and leukocytes, few data are available showing that NO donor drugs influence the extent of subchronic vascular inflammation and response to injury. Inhalation of NO (Lee et al, 1996), NO delivered as an S-nitroso derivative of albumin (Marks et al, 1995) and the peroxynitrite-generating drug molsidomine (De Meyer et al, 1995; Kalinowski et al, 2001), all have been shown to reduce neointimal expansion in animal models. Similarly, administration of the NO synthase substrate, L-arginine, reduces neointimal progression in injury models (Kalinowski et al, 2001; Vermeersch et al, 2001). Mechanistically, these agents appear to exert a beneficial effect by reducing the infiltration of leukocytes and macrophages and by decreasing intimal cell number. In a prospective clinical trial comparing $\mathrm{NO}$ donors to diltiazem in patients undergoing angioplasty, the NO donor linsidomine infusion followed by oral molsidomine improved angiographic scores compared with diltiazem, but did not appear to improve clinical events such as mortality, acute myocardial infarction occurrence rate, and recurrence rate (Lablanche et al, 1997). The lack of efficacy of the NO donor in this trial may be due to the fact that molsidomine is a peroxynitrite-generating $\mathrm{NO}$ donor. Thus, although the potential clinical utility of $\mathrm{NO}$ donors is great, the number of preclinical and clinical studies are limited.

The discovery of NO-containing NSAIDs and the NO derivative of aspirin may provide a rational approach to the treatment of chronic inflammatory diseases whereby the efficacy of well-described NSAIDs are maintained and $\mathrm{NO}$ release from the parent drug alleviates the rate-limiting side effect of gastric irritation and ulceration (Wallace et al, 1995a). With respect to the cardiovascular actions of these NO-linked drugs, the combination of NO with ASA is particularly 


\section{$H \& E$}
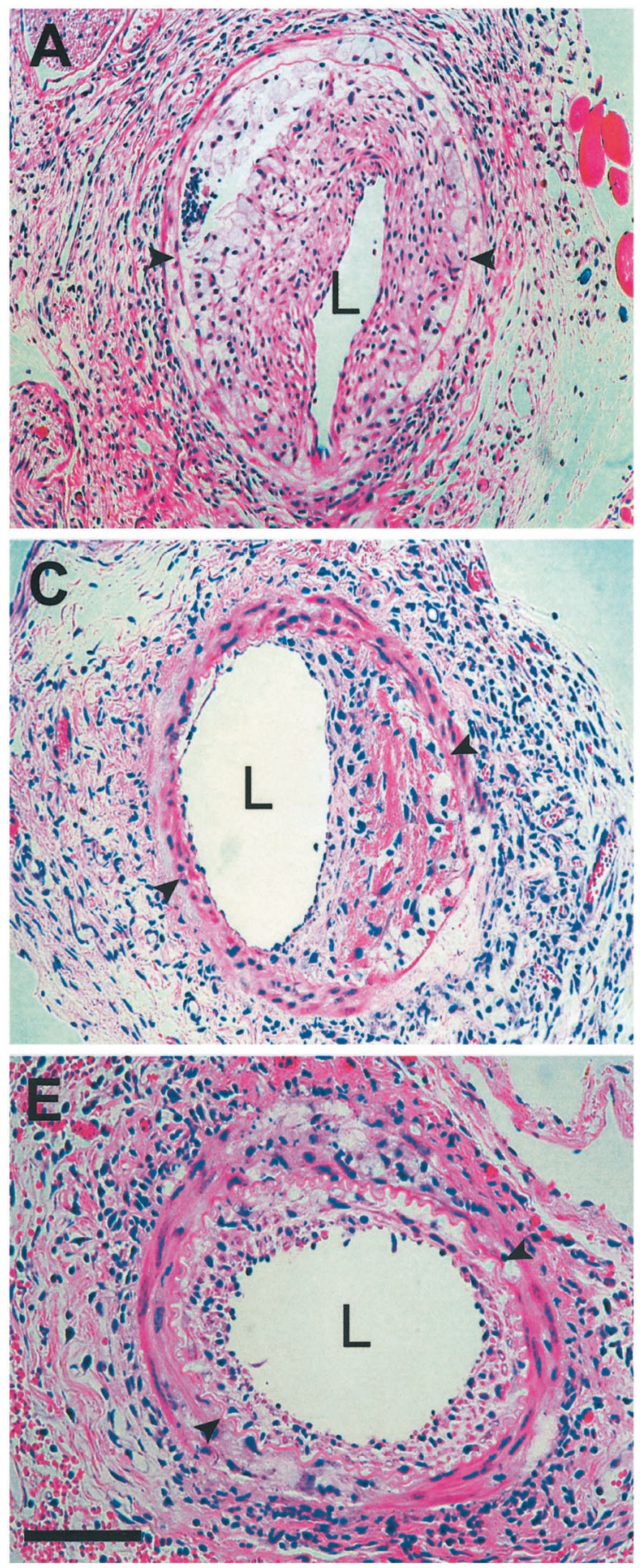

EVG
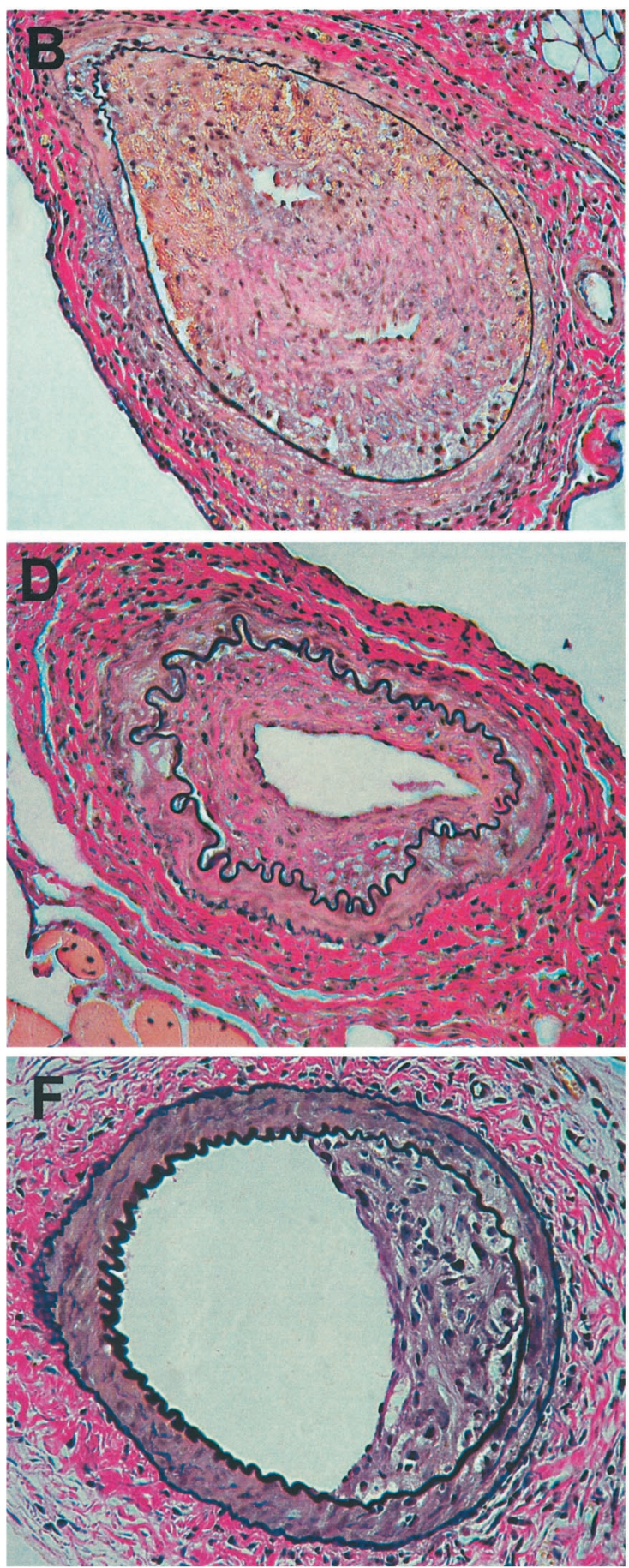

\section{Figure 1.}

The nitric oxide-releasing form of aspirin (NO-ASA) promotes luminal remodeling of injured femoral arteries from treated ApoE(-/-) mice. Representative photomicrographs of hematoxylin and eosin (H\&E) staining (Panels A, C, and E), and elastic and Van-Gieson (EVG) staining (Panels B, D, and F). Paraffin sections of the arteries were obtained 21 days after injury. Drugs were given 5 days before and 21 days after injury. Vehicle ( $A$ and B), ASA (C and D), and NO-ASA (E and F). Arrowheads show internal elastic lamina (IEL). L, lumen. Scale bar indicates $75 \mu \mathrm{m}$.

attractive to perhaps augment the well-documented cardioprotective actions of ASA. Interestingly, these drugs do not acutely lower blood pressure in normotensive rats, but can modestly reduce systemic pressures in hypertensive rats (Muscara et al, 2000, 2001).
NO released from NSAIDs or ASA can exert an antiplatelet effect and improve blood flow under conditions of ischemia (Muscara et al, 2001; Wallace et al, 1995b, 1999). Given that aspirin-like drugs have little or no effect on restenosis in humans (Folts et al, 1999; 
Table 2. Morphometric Analysis of Femoral Artery Sections

\begin{tabular}{lccc}
\hline & Vehicle $(n=7)$ & ASA $(n=6)$ & NO-ASA $(n=6)$ \\
\hline EEL diameter $(\mu \mathrm{m})$ & $274.78 \pm 16.98$ & $268.92 \pm 11.34$ & $283.68 \pm 16.28$ \\
Media area $\left(\mu \mathrm{m}^{2}\right)$ & $16464 \pm 1304$ & $16601 \pm 1317$ & $16661 \pm 1377$ \\
Intimal area $\left(\mu \mathrm{m}^{2}\right)$ & $25147 \pm 3902$ & $19425 \pm 2458$ & $12308 \pm 2464^{*}$ \\
\hline
\end{tabular}

Data are expressed as mean \pm SEM

* Denotes $p<0.05$ versus vehicle.

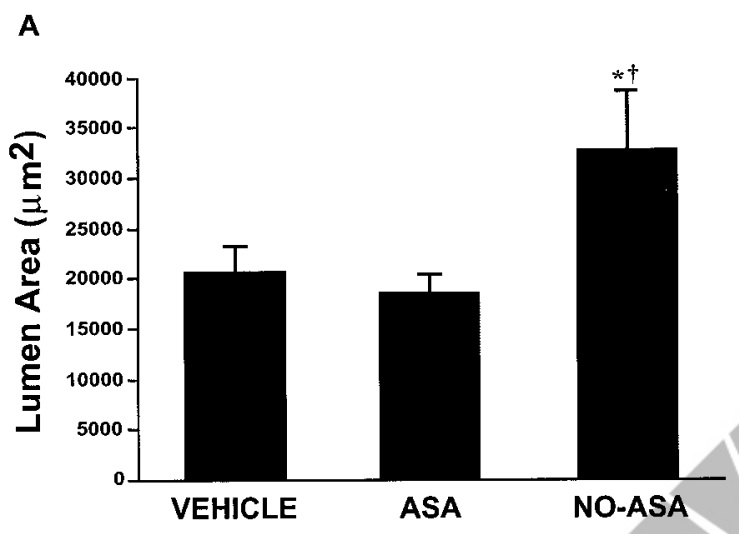

B

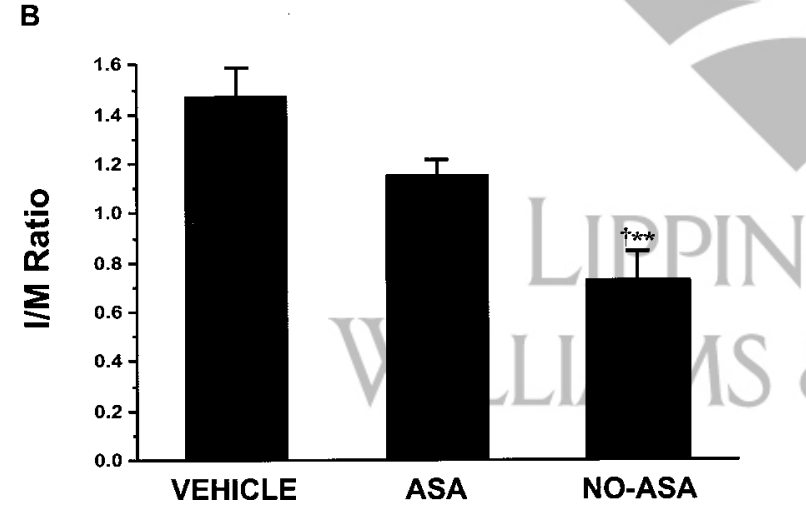

Figure 2.

NO-ASA, but not ASA, increases lumen area and improves $I / M$ ratio in he femoral artery of injured $\mathrm{ApoE}(-/-)$ mice. Morphometric quantification of the lumen area of injured femoral arteries from $A p o E(-/-)$ mice. Femoral arteries were harvested 21 days after injury in different treatment groups: Vehicle, ASA, and NO-ASA. In A, lumen area was calculated by measuring the lumen circumference. In B, intimal area was calculated by subtracting lumen area from internal elastic lamina area, and the media area was calculated by subtracting the internal elastic lamina area from the external elastic lamina area. ${ }^{*} p<0.05$ versus vehicle; ${ }^{* *} p<0.001$ versus vehicle; $\dagger p<0.05$ versus ASA.

Lefkovits and Topol, 1997), the combination of NO with aspirin may improve the anti-platelet efficacy of aspirin, and provide additional pharmacologic properties that influence the process of restenosis.

From a mechanistic perspective, the decrease in vascular inflammation seen with NO-ASA is not surprising; however, the presence of large areas of TUNEL-positive apoptotic cells is particularly striking and novel. In the context of physiologic vascular remodeling, there is evidence that hemodynamic changes can trigger medial apoptosis and a reduction in lumen diameter (Cho et al, 1997; Rudic et al, 2000).
Indeed, NO can be either pro- or antiapoptotic, and much literature supports both actions of this free radical gas (Beltran et al, 2000; Brune et al, 1999; Kim et al, 1999, 2001). The proapoptotic actions of NO are thought to be due to inhibition of mitochondrial respiration, or via the diffusion-limited interaction of NO with superoxide to generate the potent oxidant, peroxynitrite. In turn peroxynitrite can promote apoptosis. In contrast, the antiapoptotic actions are likely due to S-nitrosylation reactions occurring on specific proteins involved in the cell death pathway (Liu and Stamler, 1999). For example, nitrosylation of specific cysteine residues in caspases 3 and 8 renders them less active, thus reducing caspase-dependent cell death (Stamler et al, 2001). The higher levels of TUNEL-positive cells in injured vessels from NO-ASAtreated mice suggests that during transition of a relatively quiescent structure to an actively remodeling vessel, NO can trigger apoptosis during remodeling, thus reducing luminal expansion. Although not documented in our study, NO donor drugs can reduce vascular cell proliferation through a cGMP-dependent mechanism (Garg and Hassid, 1989) or cGMPindependent pathways (Ignarro et al, 2001) and/or via induction of cell cycle inhibitory molecules such as p21 (Waf1/Cip1/Sdi1) or p27 (Kip1) (Bauer et al, 2001; Guo et al, 1998; Holt, 2000). Pertinent to our study, perhaps NO can selectively trigger apoptosis in a fraction of cells undergoing G1-S transition, postinjury. This proapoptotic effect of NO-ASA, in addition to its anti-proliferative and anti-inflammatory actions, promotes beneficial luminal remodeling post-injury and suggests that this new class of drugs may be a useful agent to reduce inward luminal remodeling during restenosis secondary to angioplasty and arteriosclerosis.

\section{Materials and Methods}

\section{Animals and Treatment Protocol}

Congenic (generation 12) male ApoE-deficient mice (11 weeks of age, 26 to $30 \mathrm{~g}$ ) on a C57BL/6J background (The Jackson Laboratories, Bar Harbor, Maine) were used in this study. Mice were randomly divided into three groups and treated with vehicle (Tween-80 in water, $0.4 \mathrm{ml} / \mathrm{kg}$ body weight), ASA (30 mg/kg in vehicle), or the NO donor NCX-4016 (NO-ASA, 56 $\mathrm{mg} / \mathrm{kg}$ in vehicle) daily by gavage from 5 days before surgery to 3 weeks after. The amount of NO-ASA is identical on the molar basis to the amount of ASA administered. Mice were fed regular mouse chow 

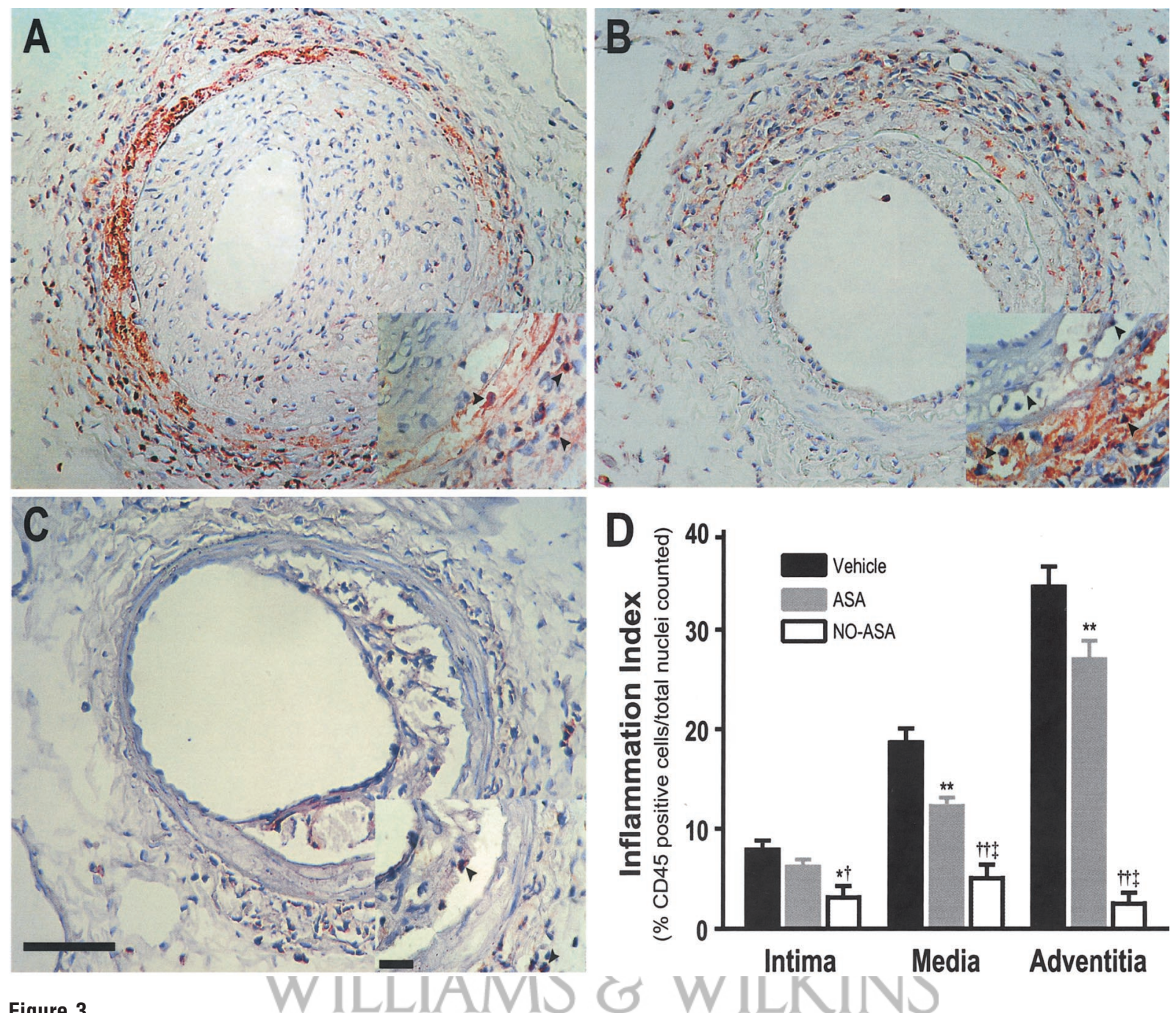

Figure 3.

NO-ASA decreases leukocyte common antigen (CD45)-positive cells in media and adventitia of injured femoral arteries from ApoE(-/-) mice. Several cross-sections per vessel ( $>$ than 3) were stained for CD45 immunohistochemical staining and developed identically. The panels are representative photomicrographs from different drug-treated groups: Vehicle (A), ASA (B), and NO-ASA (C) and respective insets of high magnification are shown. The data from multiple sections $(n=5$ vessels) are quantified in D. Arrowheads show CD45-positive cells (brown stained). Large scale bar indicates $75 \mu \mathrm{m}$ and the small bar indicates $10 \mu \mathrm{m}$. ${ }^{\star} p<0.05$ versus vehicle; $\dagger p<0.05$ versus ASA; ${ }^{* \star} p<0.01$ versus vehicle; $\dagger+p<0.01$ versus $A S A ; ~ \neq p<0.001$ versus vehicle.

throughout the experimental period. The Institutional Animal Care and Use Committee of Yale University approved all procedures.

\section{Surgical Procedures}

After anesthesia with ketamine/xylazine $(79.5 \mathrm{mg} / \mathrm{kg}$ ketamine, $9.1 \mathrm{mg} / \mathrm{kg}$ xylazine), femoral arteries were gently exposed from the inguinal ligament to the proximal part of the great saphenous artery (one branch of the femoral artery) by blunted dissection under a dissection microscope. The accompanying femoral nerve and femoral vein were dissected free from the artery. The saphenous artery was ligated distally by a 9-0 nylon suture (USSC, Norwalk, Connecticut) for reverse blood control and another 9-0 suture looped the proximal part of great saphenous artery. Clamping at the proximal site of femoral artery temporally stopped blood flow. Arterioctomy was made in the great saphenous artery with a 30-gauge needle, and a $0.25 \mathrm{~mm}$ diameter angioplasty guidewire (Advanced Cardiovascular Systems, Temecula, California) was introduced into the femoral artery. Using this guidewire, a wire to vessel diameter ratio of 1.8 was attained similar to that used in clinical angioplasty. The wire was inserted and withdrawn three times with twisting. After the wire was removed from the artery, the suture looped at the proximal portion of the saphenous artery was tightened. Blood flow of the femoral artery was restored and the skin incision closed with a 5-0 silk suture. This model was similar to a reported method (Roque et al, 2000), except that the wire insertion site was moved distally to the great saphenous artery, allowing greater restoration of blood flow after injury. In preliminary experiments measuring femoral arterial blood flow using a Transonic flow probe $(0.5 \mathrm{~mm}$; Transonic Systems, Ithaca, New York), ligation of the saphenous artery did not reduce blood flow to the same extent as does distal 
A

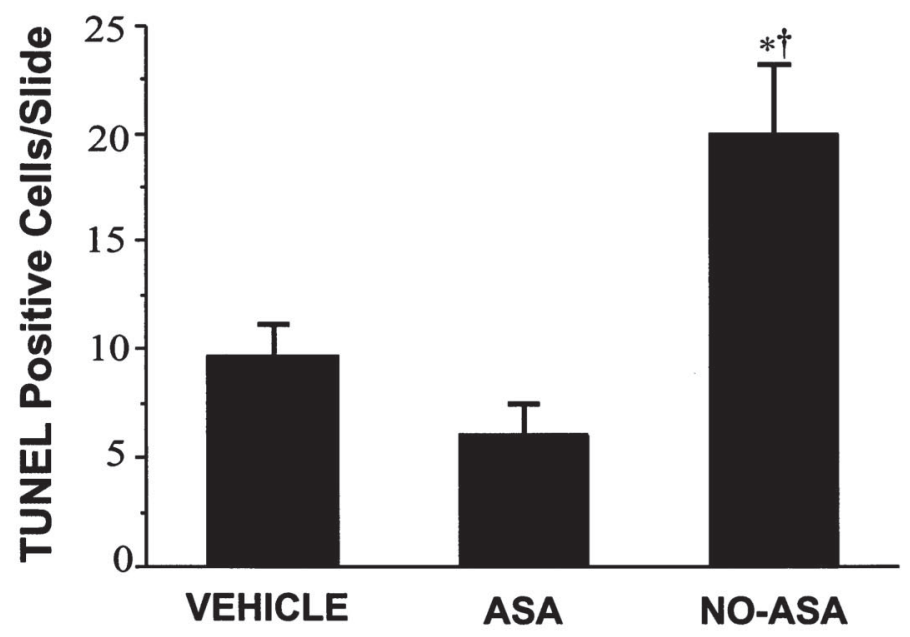

B

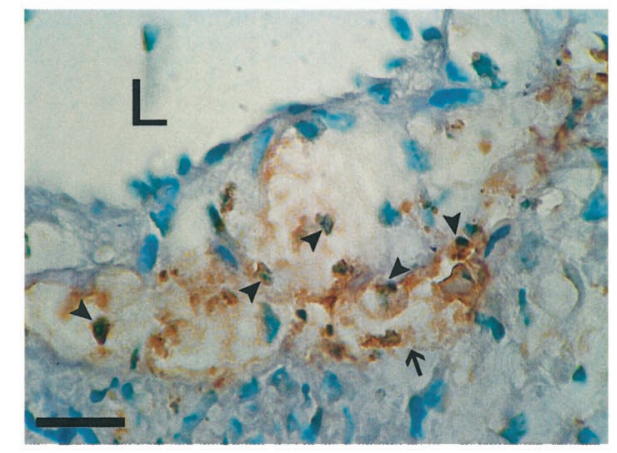

\section{Figure 4.}

NO-ASA increases the presence of TUNEL-positive cells in the media of injured femoral arteries from ApoE (-/-) mice. In A, at least three cross-sections per vessel were stained for TUNEL-positive nuclei and the number of positive cells per section quantified. Data are mean \pm SEM with $n=5$ mice per group. ${ }^{*} p<0.05$ versuS $\mathrm{V} ; \dagger p<0.05$ versus ASA. B shows a representative photomicrograph depicting TUNEL-positive nuclei in the media and neointima of vessels from a NO-ASA-treated ApoE(-/-) mouse. Arrow shows external elastic lamina (EEL). Arrowheads show TUNEL-positive cells. $L$ represents lumen. Scale bar indicates $10 \mu m$.

femoral artery ligation, thus reducing the inward remodeling triggered by a hemodynamic change. Removal of the endothelium was confirmed by Evan's blue staining in injured mice compared with noninjured, age-matched C57BL/6J mice, and reproducible neointimal formation was also observed.

Mice were killed 21 days after surgery. After anesthesia, an incision was made at the inferior vena cava and a 23-gauge needle with tubing was inserted into the left ventricle. The mouse was perfused with PBS to drain the blood and fixed with $4 \%$ paraformaldehyde in PBS at $37^{\circ} \mathrm{C}$ with physiologic pressure (100 $\mathrm{mmHg}$ ). The femoral artery segment between the inguinal ligament and the inferior epigastric branch was harvested and cut into two equal parts transversely. The proximal part was embedded in paraffin for H\&E and EVG stain. The distal part was post-fixed in $4 \%$ paraformaldehyde at $4^{\circ} \mathrm{C}$ for 2 hours, and dehydrated in $15 \%$ sucrose in PBS overnight at $4^{\circ} \mathrm{C}$, and embedded in O.C.T. (Sakura Finetek USA, Torrance, California), frozen in liquid nitrogen, and stored in $-80^{\circ} \mathrm{C}$ for immunohistochemistry and TUNEL staining.

\section{Serum Cholesterol Level Analysis}

Total serum cholesterol levels were measured in blood samples by an enzymatic immunoassay at the day of surgery and the day the rats were killed. Briefly, $150 \mu \mathrm{l}$ of blood samples were harvest in heparinized tubes by orbital sinus or inferior vena cava blood collection, and centrifuged for 10 minutes at $700 \times g$. Serum $(15 \mu l)$ was added to $500 \mu \mathrm{l}$ of Cholesterol Reagent (Sigma, St. Louis, Missouri), mixed by gentle inversion, incubated for 10 minutes at $25^{\circ} \mathrm{C}$. The absorbance of the sample was read at $500 \mathrm{~nm}$ with UV-VIS recording spectrophotometer (Shimadzu, Canby, Oregon). The total cholesterol level was calculated by converting the absorbance of a known calibrator concentration.

\section{Morphometric Analysis}

Paraffin-embedded cross-sections (5 $\mu \mathrm{m}$ thick) were stained with hematoxylin and eosin (H\&E) solution (Sigma), and EVG staining was performed using the Elastic Stain kit (Sigma). Ten sections of each femoral artery sample from $\mathrm{V}(n=7)$, ASA $(n=6)$, NO-ASA ( $n$ = 6) were used for morphometric analysis. Images were captured using a CCD camera (DAGE-MTI) mounted in a microscope (Zeiss, Thornwood, New York). Circumferences of external elastic lamina, internal elastic lamina, and lumen were measured using Scion Image software (Scion, Frederick, Maryland). Then, lumen diameter, media area, intimal area, lumen area, and intima media ratio (I/M) were calculated.

\section{Immunohistochemical Staining}

At least three frozen sections $(5 \mu \mathrm{m})$ of each group were stained. Endothelial cells and leukocytes were labeled with anti-CD31 (PECAM-1; PharMingen, San Diego, California) antibody and anti-CD45 (Leukocyte Common Antigen, ly-5; PharMingen) antibodies, respectively, followed by biotinylated IgG-streptavidinHRP and detection with DAB (Vector Laboratories, Burlingame, California) or Nova Red (Vector Laboratories). Counterstaining was performed with hematoxylin (Sigma). CD45-positive cells in the intima, media, and adventitia were analyzed in three sections of five different arteries from different treatment groups.

\section{TUNEL Staining and Apoptotic Cell Counting}

Frozen sections were used for TUNEL staining. Terminal deoxynucleotidyl transferase (TdT) enzyme was 
used to detect apoptotic cells using the manufacturer's protocol (Intergen, Purchase, New York). Methyl green $(0.5 \%)$ was used for counterstaining the specimens. Sections of normal female rodent mammary gland were used as a positive control. Three sections of five different arteries from different groups were observed. Cells with clearly discernible dark brown nuclei were counted as apoptotic cells and the number of apoptotic cells per section was compared between the groups.

\section{Statistics}

All data were expressed as mean $\pm \mathrm{SEM}$, with $n=$ the number of femoral arteries per group. Significant differences were analyzed using one-way ANOVA, followed by Bonferroni analysis. Statistical significance was defined as $p<0.05$.

\section{Acknowledgements}

We would like to thank Dr. Piero Del Sodato (NicOx S.A.) for the generous supply of NO-ASA (NCX-4016) and Dr. Giuseppe Cirino for many helpful discussions.

\section{References}

Bauer PM, Buga GM, and Ignarro LJ (2001). Role of p42/p44 mitogen-activated-protein kinase and p21waf1/cip1 in the regulation of vascular smooth muscle cell proliferation by nitric oxide. Proc Natl Acad Sci USA 98:12802-12807.

Beltran B, Mathur A, Duchen MR, Erusalimsky JD, and Moncada S (2000). The effect of nitric oxide on cell respiration: A key to understanding its role in cell survival or death. Proc Natl Acad Sci USA 97:14602-14607.

Brune B, von Knethen A, and Sandau KB (1999)/Nitric oxide (NO): An effector of apoptosis. Cell Death Differ 6:969-975.

Cho A, Mitchell L, Koopmans D, and Langille BL (1997). Effects of changes in blood flow rate on cell death and cell proliferation in carotid arteries of immature rabbits. Circ Res 81:328-337.

Cooke JP, Dzau J, and Creager A (1991). Endothelial dysfunction in hypercholesterolemia is corrected by L-arginine. Basic Res Cardiol 86:173-181.

De Meyer GR, Bult H, Ustunes L, Kockx MM, Feelisch M, and Herman AG (1995). Effect of nitric oxide donors on neointima formation and vascular reactivity in the collared carotid artery of rabbits. J Cardiovasc Pharmacol 26:272-279.

Folts JD, Schafer AI, Loscalzo J, Willerson JT, and Muller JE (1999). A perspective on the potential problems with aspirin as an antithrombotic agent: A comparison of studies in an animal model with clinical trials. J Am Coll Cardiol 33:295303.

Garg UC and Hassid A (1989). Nitric oxide-generating vasodilators and 8-bromo-cyclic guanosine monophosphate inhibit mitogenesis and proliferation of cultured rat vascular smooth muscle cells. J Clin Invest 83:1774-1777.

Girerd XJ, Hirsch AT, Cooke JP, Dzau VJ, and Creager MA (1990). L-arginine augments endothelium-dependent vasodilation in cholesterol-fed rabbits. Circ Res 67:1301-1308.

Giugliano D, Marfella R, Acampora R, Giunta R, Coppola L, and D'Onofrio $F$ (1998). Effects of perindopril and carvedilol on endothelium-dependent vascular functions in patients with diabetes and hypertension. Diabetes Care 21:631-636.

Guo K, Andres V, and Walsh K (1998). Nitric oxide-induced downregulation of cdk2 activity and cyclin a gene transcription in vascular smooth muscle cells. Circulation 97:20662072.

Harrison DG (1997). Cellular and molecular mechanisms of endothelial cell dysfunction. J Clin Invest 100:2153-2157.

Holt CM (2000). Enos inhibition of proliferation: A role for p21(sdi1/cip1/waf1) and p27(kip1). Cardiovasc Res 47:640641.

Ignarro LJ, Buga GM, Wei LH, Bauer PM, Wu G, and del Soldato $P$ (2001). Role of the arginine-nitric oxide pathway in the regulation of vascular smooth muscle cell proliferation. Proc Natl Acad Sci USA 98:4202-4208.

Kalinowski M, Alfke H, Bergen S, Klose KJ, Barry JJ, and Wagner HJ (2001). Comparative trial of local pharmacotherapy with L-arginine, R-hirudin, and molsidomine to reduce restenosis after balloon angioplasty of stenotic rabbit iliac arteries. Radiology 219:716-723.

Kim PK, Zamora R, Petrosko P, and Billiar TR (2001). The regulatory role of nitric oxide in apoptosis. Int Immunopharmacol 1:1421-1441.

Kim YM, Bombeck CA, and Billiar TR (1999). Nitric oxide as a bifunctional regulator of apoptosis. Circ Res 84:253-256.

Lablanche JM, Grollier G, Lusson JR, Bassand JP, Drobinski G, Bertrand B, Battaglia S, Desveaux B, Juilliere Y, Juliard JM, Metzger JP, Coste P, Quiret JC, Dubois-Rande JL, Crochet PD, Letac B, Boschat J, Virot P, Finet G, Le Breton $H$, Livarek B, Leclercq F, Beard T, Giraud T, McFadden EP, and Bertrand ME (1997). Effect of the direct nitric oxide donors linsidomine and molsidomine on angiographic restenosis after coronary balloon angioplasty: The accord study. Angioplastic coronaire corvasal diltiazem. Circulation 95:8389.

Lee JS, Adrie C, Jacob HJ, Roberts JD Jr, Zapol WM, and Bloch KD (1996). Chronic inhalation of nitric oxide inhibits neointimal formation after balloon-induced arterial injury. Circ Res 78:337-342.

Lefkovits J and Topol EJ (1997). Pharmacological approaches for the prevention of restenosis after percutaneous coronary intervention. Prog Cardiovasc Dis 40:141-158.

Liu L and Stamler JS (1999). NO: An inhibitor of cell death. Cell Death Differ 6:937-942.

Mancini GB, Henry GC, Macaya C, O'Neill BJ, Pucillo AL, Carere RG, Wargovich TJ, Mudra H, Luscher TF, Klibaner MI, Haber HE, Uprichard AC, Pepine CJ, and Pitt B (1996). Angiotensin-converting enzyme inhibition with quinapril improves endothelial vasomotor dysfunction in patients with coronary artery disease: The TREND (trial on reversing endothelial dysfunction) study. Circulation 94:258-265.

Marks DS, Vita JA, Folts JD, Keaney JF Jr, Welch GN, and Loscalzo J (1995). Inhibition of neointimal proliferation in rabbits after vascular injury by a single treatment with a protein adduct of nitric oxide. J Clin Invest 96:2630-2638.

Moncada S (1997). Nitric oxide in the vasculature: Physiology and pathophysiology. Ann NY Acad Sci 811:60-67; discussion 67-69. 
Muscara MN, Lovren F, McKnight W, Dicay M, del Soldato P, Triggle CR, and Wallace JL (2001). Vasorelaxant effects of a nitric oxide-releasing aspirin derivative in normotensive and hypertensive rats. Br J Pharmacol 133:1314-1322.

Muscara MN, McKnight W, Lovren F, Triggle CR, Cirino G, and Wallace $\mathrm{JL}$ (2000). Antihypertensive properties of a nitric oxide-releasing naproxen derivative in two-kidney, one-clip rats. Am J Physiol Heart Circ Physiol 279:H528-535.

Napoli C, Cirino G, Del Soldato P, Sorrentino R, Sica V, Condorelli M, Pinto A, and Ignarro LJ (2001). Effects of nitric oxide-releasing aspirin versus aspirin on restenosis in hypercholesterolemic mice. Proc Natl Acad Sci USA 98:28602864.

Papapetropoulos A, Rudic RD, and Sessa WC (1999). Molecular control of nitric oxide synthases in the cardiovascular system. Cardiovasc Res 43:509-520.

Roque M, Fallon JT, Badimon JJ, Zhang WX, Taubman MB, and Reis ED (2000). Mouse model of femoral artery denudation injury associated with the rapid accumulation of adhesion molecules on the luminal surface and recruitment of neutrophils. Arterioscler Thromb Vasc Biol 20:335-342.

Rudic RD, Bucci M, Fulton D, Segal SS, and Sessa WC (2000). Temporal events underlying arterial remodeling after chronic flow reduction in mice: Correlation of structural changes with a deficit in basal nitric oxide synthesis. Circ Res 86:1160-1166.

Rudic RD and Sessa WC (1999). Nitric oxide in endothelial dysfunction and vascular remodeling: Clinical correlates and experimental links. Am J Hum Genet 64:673-677.

Stamler JS, Lamas S, and Fang FC (2001). Nitrosylation: The prototypic redox-based signaling mechanism. Cell 106:675683.

Tzeng E, Shears LL II, Robbins PD, Pitt BR, Geller DA, Watkins SC, Simmons RL, and Billiar TR (1996). Vascular gene transfer of the human inducible nitric oxide synthase: Characterization of activity and effects on myointimal hyperplasia. Mol Med 2:211-225.
Vaughan CJ, Murphy MB, and Buckley BM (1996). Statins do more than just lower cholesterol. Lancet 348:1079-1082.

Vermeersch P, Nong Z, Stabile E, Varenne O, Gillijns H, Pellens M, Van Pelt N, Hoylaerts M, De Scheerder I, Collen D, and Janssens $S$ (2001). L-arginine administration reduces neointima formation after stent injury in rats by a nitric oxide-mediated mechanism. Arterioscler Thromb Vasc Biol 21:1604-1609.

von der Leyen HE, Gibbons GH, Morishita R, Lewis NP, Zhang L, Nakajima M, Kaneda Y, Cooke JP, and Dzau VJ (1995). Gene therapy inhibiting neointimal vascular lesion: In vivo transfer of endothelial cell nitric oxide synthase gene. Proc Natl Acad Sci USA 92:1137-1141.

Wallace JL, McKnight W, Del Soldato P, Baydoun AR, and Cirino G (1995a). Anti-thrombotic effects of a nitric oxidereleasing, gastric-sparing aspirin derivative. J Clin Invest 96:2711-2718

Wallace JL, Muscara MN, McKnight W, Dicay M, Del Soldato $P$, and Cirino $G$ (1999). In vivo antithrombotic effects of a nitric oxide-releasing aspirin derivative, ncx-4016. Thromb Res 93:43-50.

Wallace JL, Pittman QJ, and Cirino G (1995b). Nitric oxidereleasing NSAIDs: A novel class of Gl-sparing antiinflammatory drugs. Agents Actions 46(Suppl):121-129.

Wallace JL, Reuter BK, and Cirino G (1994). Nitric oxidereleasing non-steroidal anti-inflammatory drugs: A novel approach for reducing gastrointestinal toxicity. J Gastroenterol Hepatol 9(Suppl 1):40-44.
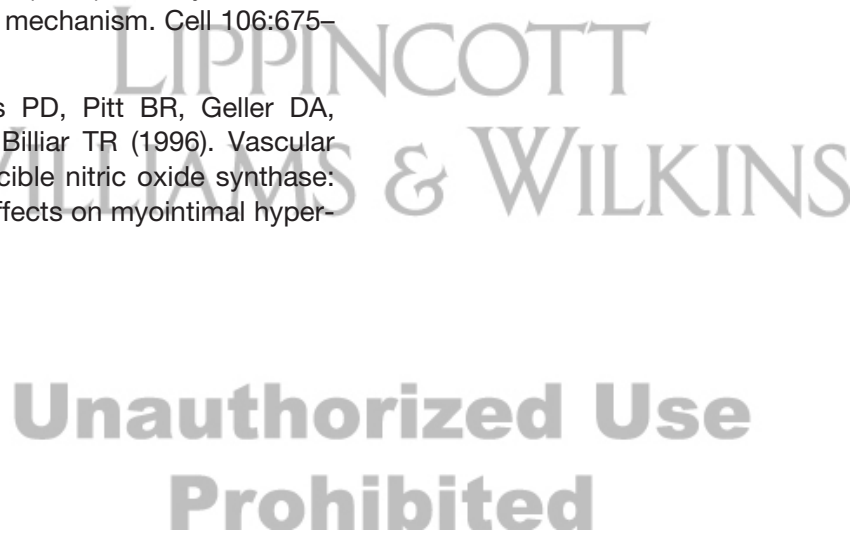